\title{
TOWARDS SUSTAINABLE URBAN TRANSPORT (CASE OF THE TRAMWAY OF THE CITY OF CONSTANTINE)
}

\author{
Boufendassa Rima ${ }^{1}$, Huang Yue Hao ${ }^{2}$ \\ ${ }^{1}$ Address (ADR) Lanzhou Jiaotong University - China \\ ${ }^{2}$ Address (ADR) Lanzhou Jiaotong University -China
}

\begin{abstract}
The future of the ecological and environmental equilibrium of the whole planet is shaken up following the speedy growth of atmospheric pollution and the progressive alteration of the climatologically characteristics. The transportation sector is considered the primary source of greenhouse gas emissions and pollutants in the atmosphere.

As a result, the reduction of this pollution has become one of the major challenges of environmental protection. In this sense, the Algerian state has gradually begun to become aware of the need to introduce the environmental dimension to the development strategy of the environment, Countries through the initiation of legislative, regulatory and institutional actions and a new sustainable transport policy. Algeria's efforts to preserve the environment and reduce the degree of atmospheric pollution associated with the transport sector have resulted in the adoption of sustainable transport means on the ground; as a case study, the tramway initiated in the city of Constantine.
\end{abstract}

Keywords: Air Pollution, Environmental Strategy, Sustainable Transport, Tramway, Constantine $* * *$

\section{INTRODUCTION}

The rapid increase in atmospheric pollution and the gradual change in climatic characteristics, are elements that indicate that the future of ecological and environmental balance of the whole planet happens to be disturbed. While the industry sector has long been considered as the main source of this pollution, it is clear that the transport sector is gaining the upper hand and becoming the primary source of greenhouse gas emissions and polluting substances. The atmosphere. Tangentially, the most affected countries are aware of the need to reduce this pollution and to orient their policy towards a development guaranteeing the ecological balance of the environment. In this sense, several summits have been held, to note the first Earth Summit held in Rio in 1992 which kicked off a real sustainable development policy on a global scale, the second one which took place held in Johannesburg in 2002 which recommended the need for rapid progress and the Conference of Copenhagen in 2009 on climate change. Algeria has gradually become aware of the need to take into account the ecological aspects and to introduce the environmental dimension to the country's development strategy through the signing of the Framework Convention on Climate Change, in Particularly the stabilization of greenhouse gas emissions and the initiation of a voluntarist policy based on the maximum use of natural gas.

The following text attempts to show from the analysis of a reality on the ground, the efforts of our country to preserve the environment and reduce the degree of air pollution related to the transport sector. These efforts have resulted in the adoption of sustainable means of transport, as a case study, the tramway initiated in the city of Constantine.

\section{BIRTH OF A REAL STRATEGIENATIONAL ENVIRONMENTAL (SNE) IN ALGERIA}

Algeria's interest in preserving environmental quality began very early in the 1970 s with Algeria's participation in the first World Conference in Stockholm (1972) under the auspices of Algeria. United Nations, which considers that any long-term policy is only conceivable in an international context. This participation was followed by the founding of the National Environment Committee (NCW) in 1974 whose mission is to propose the essential constituents of environmental insurance.

In 1983, Law 83-03 of 5 February 1983 on the protection of the environment reinforced this interest by encouraging the creative activity of the National Agency for the Protection of the Environment (A.N.P.E.). This law specifies the protection and the valorization of the natural resources, the prevention and fight against whatever form of pollution and nuisance and the improvement of the material body and quality of liveliness.

The property of the summits of Rio (1992) and Johannesburg (2002), substantially reinforced the efforts of the Algerian nation. Gradually, awareness for the preservation of the environment in the context of sustainable development becomes not only a guarantee of sustainability, but also of stability of economic and social growth. 
This business has been consolidated by the formation of a national strategy for the conservation of the environment through the National Action Plan for the Environment and Sustainable Development (PNAE-DD) in the fabric of the first National Report on the State and the Future of the Environment (RNE2000) adopted by the Council of Ministers of 12 August 2001. This story identifies the physical and institutional vulnerability factors and the commonwealth of the environment.

It outlines the national environment strategy in line with the country's socioeconomic priorities, and suggests an emergency plan. A team of Algerian consultants has prepared reference documents on industrial pollution, urban pollution, air contamination, water resources, natural resources, coastal zone management, archaeological heritage, public health, and institutional and legal views.

As an outcome, the environmental strategy in Algeria is consolidated by three elements:

-A consistent legislative framework

- Strong institutional capacity

- Clear economic and financial instruments.

\subsection{A Consistent Legislative Framework}

Algeria is committed to the proclamation of a corpus of texts:

- Law 01-19 of 12 December 2001 on the management, control and disposition of waste.

In the application of this law, it has been put up:

- A National Special Waste Management Plan (PNAGDES),

a rational and ecological management that is part of the National Environmental Strategy (SNE), as good as in the National Plan of Environmental Actions and Sustainable Development (PNAE-DD).

- A National Program for the Management of Municipal Solid Waste (PROGDEM), guaranteeing the security of the environment and the conservation of the hygiene of the surroundings, notably through the structure, development and equipping of technical landfills (CET) in the urban centers. These priority actions are initiated by the Ministry of Environment MATE

- Law 03-10 of 19 July 2003 on the protection of the environment in the context of sustainable growth. It sets down the basic precepts and regulations of environmental management: the protection, restructuring and enhancement of natural resources; the return of damaged environments, the prevention and the fight against whatever form of pollution and nuisance; improving the quality of life and the environment, raising the intellectual function of using natural resources.

The law shows the prerequisites for the protection of biological diversity, air and the atmosphere, water and aquatic environments, soil and soil, desert environments, the sea and the land of life.

\subsection{Strong Institutional Capacity}

Awareness of environmental issues in Algeria is linked to the main stages of institutional evolution, since the creation of the National Council of the Environment (CNE) in 1974, an advisory body whose mission is to propose the essential elements of environmental policy in the framework of spatial planning and economic and social development, until the creation of the Ministry of Territorial Development and Environment (MATE) in 2000, which became (MATET) in 2007 (associating the tourism sector)

Other national organizations related with events have emerged in the environmental field, including:

- SECE (State Secretariat for the Environment)

- PNAE (National Environmental Action Plan)

- HCEDD (Office of the High Commissioner for the Environment and Sustainable Development)

- FNE (National Fund for the Environment)

- ONEDD (National Observatory of the Environment and Sustainable Development)

- AND (National Waste Agency)

- CNTPP (National Center of Plus Proper's Technologies)

- CNFE (National Conservatory of Environmental Training)

\subsection{Well-Designed Economic and Fiscal}

\section{Instruments}

The target is the generalization of environmental management arrangements and clean technologies through the Environmental and Environmental Contamination Fund (FEDEP).

Its financial endowment by the regime will enable it to assist the companies to engage in cleanup operations aimed at improving their environmental and economic functioning. The new ecological tax system will promote investment projects integrating clean technologies and safeguarding the environment. It also aims to implement the polluter pays principle.

\section{THE TRANSPORT SECTOR AND SONIMPACT ON ENVIRONMENTAL QUALITY}

In Algeria, the road transport sector in the urban environment is largely responsible for the emission of gases and pollutants into the atmosphere, which inevitably leads to atmospheric pollution and the disruption of the urban environment of our cities.

This sector is responsible for the emission of $22 \% \mathrm{CO} 2$ and $57.7 \%$ of NOx into the breeze. They get several types of pollutants, including: sulfur dioxide (SO2), carbon monoxide (CO), carbon dioxide ( $\mathrm{CO} 2)$, nitrogen dioxide (NO2) volatile organic compounds (VOC) and tip.

Their immersion in the air can lead to major risks due to their sanitary toxicity in humans (premature deaths, acute childhood bronchitis, asthma attack, eye irritation, damage 
to the immune system, and so on) as well as environmental impairment., wildlife and vegetation (decline in farming production, acidification of soil and water...)

Several factors have aggravated the degree of this contamination in urban regions,

- The energy factor and the caliber of the fuels used by the transport often not in accordance with the principles enacted in the matter of the security of the environment. One third of energy usage is due to the transport sector, and gasoline remains the main source of energy for more than $75 \%$ of vehicles. The total absence of emission control aggravates the density of road traffic, which accounts for $88 \%$ of passenger land movements and $82 \%$ of goods transport.

- The increase in the number of vehicles with an annual increase of $5 \%$ on average and the aging condition of the Algerian car fleet: it has more than 3,211,052 vehicles, with an average age of 09 years. In the case of the province of Constantine, most tourist cars are older than 10 years, which goes to the worsening of atmospheric pollution.

Faced with this annoying situation, Algeria has opted for actions aimed at bringing down the rate of pollution generated by fuels, which will lead to positive health outcomes, the decrease of cardiovascular diseases and the preservation of the surroundings. . The transportation sector has benefited from new initiatives to guarantee a clean and sustainable transport system.

\section{NEW ALGERIAN INITIATIVES FOR SUSTAINABLE TRANSPORT}

Algeria is committed to a global environmental protection policy, where the urban transport sector, the main source of atmospheric pollution, has been one of the major concerns.

With this goal, the Ministry in charge of the environment has set up, besides the laws already mentioned, a system of regularly analyzes of the air quality, called "SAMASAFIA" since April 2002. It is interested in the control of the air pollution in the most polluted urban centers of the country, namely Algiers, Annaba and Oran. Other urban agglomerations among the most important in the country will soon be equipped with similar networks.

"These networks provide continuous monitoring of the quality of the air through the measurement of the main pollutants. The accumulated information is a database that can be used to analyze and evaluate the impacts of the use of different means of road transport on the environment. Their generalization must also establish some other source of data, which builds it possible to better recognize the spot in our nation"

This policy was consolidated in particular by a national energy policy and a conversion program for liquefied petroleum gas fuel vehicles from 1982 onwards aimed at improving the quality of fuels. Other energy consumption actions have been implemented, among which are:
- The priority and maximum use of alternative fuels such as liquified petroleum gases (LPG), whose technical characteristics are more adept and more efficient on the environmental and economic strata. The share of LPG in the total use of motor fuels will reach $34 \%$ in the twelvemonth 2020

- The use of unleaded petrol for which a standard defining the chemical-chemical characteristics in force since January 1999 has been established.

- The use of compressed gaseous state $(\mathrm{CNG})$ initiated at the residual of the 1980s. The fibers of this fuel as a motor fuel, have led to a development program for the use of CNG as a fuel.

- Initiation of a scheme that focuses on reducing car traffic and prioritizing mass transport through:

- The employment of high capacity buses were 300 buses (100 seats / bus) that match the international measures have been spelled. These buses save space and reduce fuel consumption by approximately $15 \%$. The public presentation was accompanied by the creation of public companies for the management of these buses.

- The launching of subway projects in the capital and trams in major Algerian cities. The latter is boosted by the fiveyear investment plan (2004-2009) and are already funded by the companionship of the Metro meter of Algiers (EMA). Thanks to their performance with electric vitality, they anticipate a series of advantages: the reduction of atmospheric pollution as well as of the durability and modernity perspectives for the cities. The job of the tramway of the city of Constantine is now part of this approach.

\section{CASE OF "TRAMWAY PROJECT" OF THE CITY OF CONSTANTINE}

As a result of considerable urbanization, a constraining site, anarchic traffic and increasing pollution, the transport in Constantine is experiencing an alarming situation. In this determination, it has been recommended "the tramway project" for the city, which is set to be commissioned in 2012; work is already underway by the Dumet Company of Algiers (EMA).

The impact of the first appearance of the tramway on the environment. The proposed project for the city of Constantine tented to achieve a balanced development on the environmental, socioeconomic and ecological design.

Powered by electric power, the tram is considered among the least polluting ecological modes of conveyance, it produces neither smoke nor gas unlike cars. A tramway equals 3 passenger vehicles, 150 cars and it renders us more carbon dioxide. This could effectively mitigate harm to human health, including cardiovascular and respiratory diseases. All 71,434 existing tourist vehicles in Constantine can be replaced by 477 tramways (in rotation). The number of carriages and coaches can also be reduced to 603 tramways (in rotation). 
It establishes that air pollution is serenely reduced by the use of the trolley. So, for the 71434 existing vehicles in Constantine, whose turn is reduced by $0.67 \%$, the pollution can be shortened in turn by $99.33 \%$. For the existing 1809 cars and buses, the number of which is scaled down by $33.34 \%$, the contamination can be shortened by $66.66 \%$. This may be really effectual in keeping the quality of the environment of the city of Constantine.

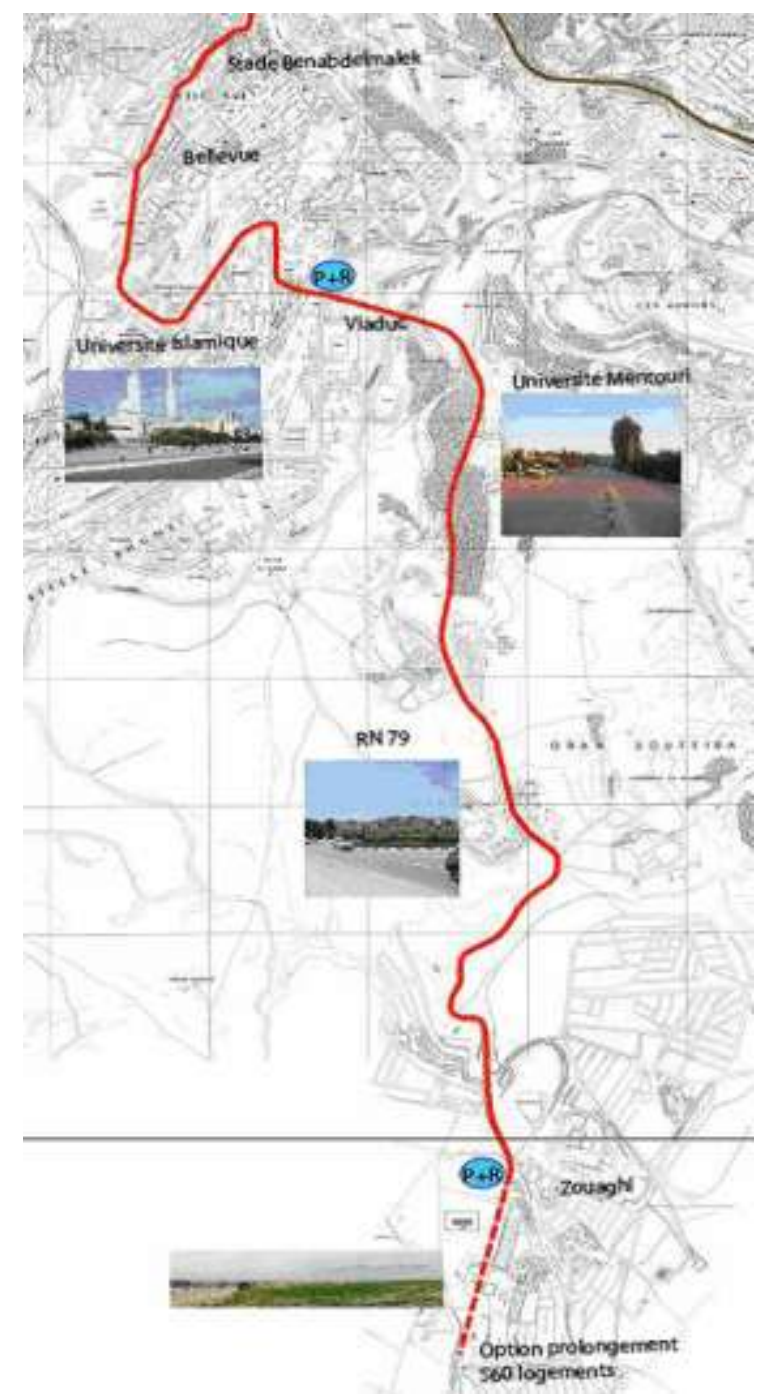

Fig 1: Initial layout of the Constantine tramway

\subsection{The Impact of Tramway Insertion on the}

\section{Surroundings}

The proposed project for the city of Constantine tries to reach a balanced development in environmental, socioeconomic and ecological conditions.

Powered by electric power, the tramway is considered among the least environmentally friendly ways of transport, it does not create smoke or gas unlike cars. A tram equals 3 passenger vehicles, 150 cars and it delivers us more carbon dioxide. This could effectively mitigate the nuisances to human health, including cardiovascular and respiratory diseases. All 71,434 existing tourist vehicles in Constantine, can be replaced by 477 (rotating) trams, the number of Autobus and Bus can also be reduced to 603tramway (in rotation) (see table 1)

Table 1: Rate of reduction of the number of existing cars in Constantine following the exercise of the tram

\begin{tabular}{|l|l|l|l|}
\hline $\begin{array}{l}\text { Type of } \\
\text { vehicle }\end{array}$ & $\begin{array}{l}\text { Number of } \\
\text { existing cars }\end{array}$ & $\begin{array}{l}\text { Number of } \\
\text { tramways } \\
\text { replacing } \\
\text { (rotating) }\end{array}$ & Reduced rate \\
\hline $\begin{array}{l}\text { Tourism } \\
\text { vehicle }\end{array}$ & 71434 & 477 & $0,67 \%$ \\
\hline $\begin{array}{l}\text { Coach } \\
\& \text { Bus }\end{array}$ & 1809 & 603 & $33.34 \%$ \\
\hline
\end{tabular}

It shows that the air pollution will actually be mitigated by the use of the tram. Thus, for the 71434 existing vehicles in Constantine, whose number is reduced by $0.67 \%$, the pollution can be reduced in turn by $99.33 \%$ (see graph 1 ) for the 1809 existing coaches and buses whose number is reduced by $33.34 \%$, pollution can be reduced in turn by $66.66 \%$ (see graph 2). This can be very effective in preserving the quality of the environment of the city. Constantine.

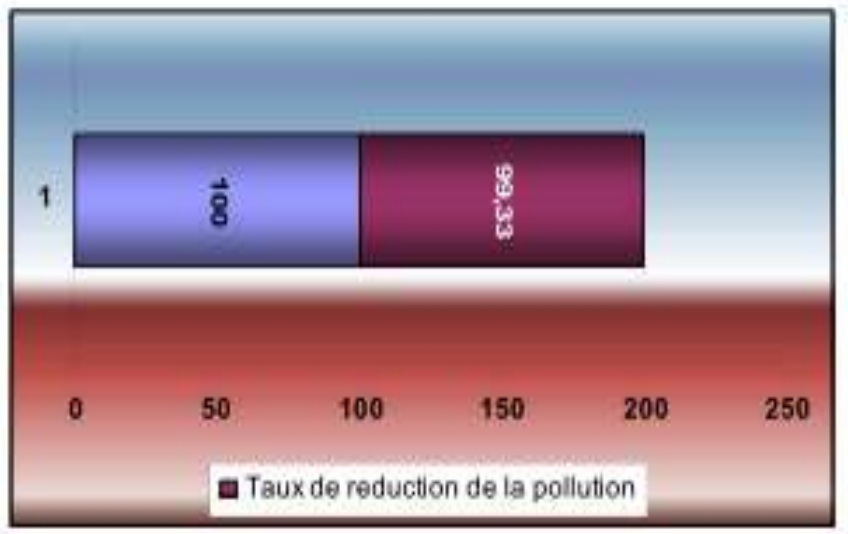

Graph 1: Pollution reduction rate, Atmospheric for Passenger vehicles

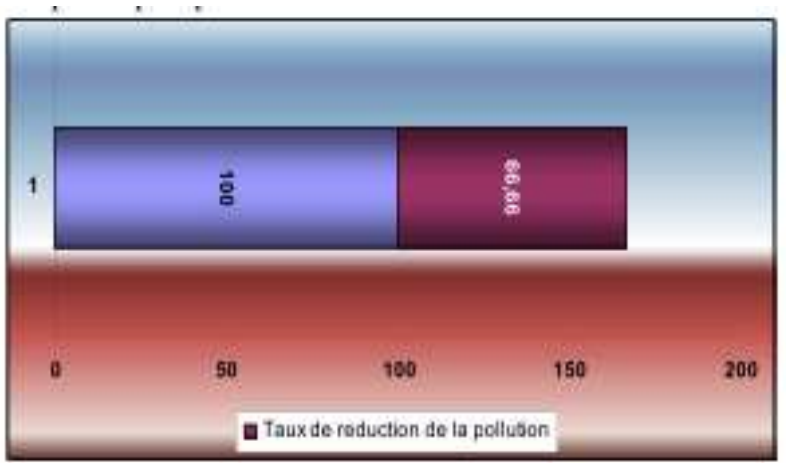

Graph 2: Pollution reduction rate, Atmospheric for Bus \& Coach 
The degradation of the environment marked by urban pollution Threatening the health of the citizen and the general environment, today it is part of our major concern.

\section{CONCLUSION}

Algeria is gradually beginning to take cognizance of the need to take ecological aspects into account and to introduce the environmental dimension into the country's development strategy. The initiation of legislative, regulatory and institutional actions of a new sustainable transport policy is proof of this.

The Algerian state has gone about 17 squads in different cities. That of Algiers has been placed into service since May 2011. The reception of those of the city of Constantine and Oran is scheduled for 2012.

The objective of accomplishing a reduction of pollution generated by the transport sector is becoming a major challenge for the protection of the environment.

The proposal for the city of Constantine's tramway project seems to be appropriate ecological solutions for a better ecological balance, effectively and sustainably preserving the quality of the air and the environment.

\section{REFERENCES}

[1] Bonnafous A., "Transport and the environment. Towards a new balance, CNT, The French Documentation. 1999

[2] François Michel, Herve Le Treut Jean-Marc "Ecology with small steps" Editions Actes Sud, 2000

[3] Gérard Mégie, "Stratosphere and layer of ozone »Editions Masson, 1992

[4] Jancovici "The greenhouse effect: Are we going to change the climate? », Editions, flammarion2001

[5] Jean Christian Lhomme, «The Energy renewable sources: history, state of play and Perspectives », 2001

[6] National Action Plan Report for environment and sustainable development

[7] A. Tony Har "Air Pollution" Gamma Editions, 1993

[8] Rabhi P, "Towards happy sobriety," Editions Actes Sud, April 2010. "The car civilization facing the challenge of sustainable development ", collective work, 2003, Edition les Annales des Mines Industrial Realities

[9] (PNAE-DD) Ministry of Planning the territory and the environment January 2002: at. Ministry Report From The layout of the territory and The environment: "The Politics Environmental, Industrial - Clean Up The Industry - »March 2003

b. SNAT: national scheme planning

c. Note of the transport strategy (World Bank January 1999)

[10] Report of WHO (World Health Organization) Health)

[11] -Report "Cities and sustainable development", http://www.urbanisme.equipement.gouv.fr Report
United Nations Conference on the environment, Stockholm, 5-16 June 1972

[12] -Annual Report SAMASAFIA, Ministry of Territorial Planning and Environment and Tourism, 2007, http://www.onedd.com.dz/SAMASAFIA2007.pdf

[13] -FESTY -B. "Urban air pollution: sources, pollutants and evolution", heat energy, 1997

[14] -Kerbachi R., Boughedaoui M., "Particulate pollution at Rais Hamidou, Algiers. Magnitude and dispersion ", Algerian Journal of Technology, 1994

[15] -Plassard F "Transport, Infrastructure and Regional Development", COST Conference, Basel, November. 1995.

[16] A.Ribouh B, Bensakhria K. "Perspectives of sustainability for an already saturated city, case of the city of Constantine" colloquium of the Department of Geography of the Faculty of Letters of Arts and Humanities, Tunisia: (dynamics, studies And environment), University - La Manouba -Tunisie, 0608 March 2008 